\title{
Frailty in the age of VIPs (very old intensive care patients)
}

\author{
Carmel Montgomery and Sean M. Bagshaw*
}

๑ 2017 Springer-Verlag GmbH Germany and ESICM

Frailty, a multi-system decline in health status resulting from the cumulative impairment of homeostatic reserve (i.e., energy, physical ability, cognition), is increasingly recognized as an important prognostic determinant of outcome among critically ill populations [1-3]. Frailty predisposes to disproportionate and heightened vulnerability to adverse outcomes from acute stressors such as infection, surgery, or trauma. As many as one-third of adult critically ill patients admitted to the intensive care unit (ICU) have been shown to be screened as frail, with the prevalence increasing with older age $[1,2,4]$.

While the prevalence of frailty may naturally increase with age, it is important to recognize that frailty and ageing are not synonymous. The accumulation of health impairments driving the development of frailty may occur at vastly different rates between individuals and across the adult lifespan [5]. Accordingly, frailty may represent a more robust predictor of vulnerability and "recoverability" than chronological age alone, particularly in the context of critical illness. Indeed, frail persons are susceptible to catastrophic multi-system organ failure from illnesses that are often tolerated by fit (not frail) persons of the same age. This may translate into greater rescue of frail patients by "intensive care" compared with contemporary age-matched fit patients. Frail patients admitted to ICU have worse outcomes, including higher mortality and among survivors, greater disability and impaired quality of life, and greater likelihood of longterm institutionalization. In this context, frailty is also increasingly recognized as a common end-of-life trajectory that is associated with considerable health resource use $[6,7]$.

\footnotetext{
*Correspondence: bagshaw@ualberta.ca

Department of Critical Care Medicine, Faculty of Medicine and Dentistry, University of Alberta, 2-124 Clinical Sciences Building, 8440-112 ST NW,
} Edmonton T6G 2B7, Canada
Accordingly, we read with interest the recent findings of the prospective, observational cohort study of 5021 very old patients [median (IQR) age 84 years (81-86)] admitted to 311 European ICUs presented by Flaatten and colleagues [Very Old Intensive Care Patients (VIP Study)] [8]. The main objective of the VIP study was to evaluate the impact of frailty on ICU and 30-day mortality, along with its association with intensity of ICU support provided.

In the VIP study, frailty status was ascertained by screening patients using the Clinical Frailty Scale (CFS) score at the time of ICU admission [1, 2]. The CFS is a previously validated judgment-based tool that can be relatively simple to use to screen patients on an visual analogue and ordinal scale (range 1-9), with higher scores representing greater degrees of frailty $[1,2,9]$. In the VIP study, the CFS was assigned by bedside physicians and nurses and aimed to integrate patient information or surrogate reporting of patient status immediately prior to the current illness. Patients were classified as fit (CFS score 1-3), pre-frail (CFS score 4) or frail (CFS score 5-9), respectively.

The VIP study found $42.9 \%$ of patients aged $\geq 80$ years old admitted to ICU were screened as frail. Description of the cohort further showed that frail patients were older, more likely female, had higher admission sequential organ failure assessment scores, were more likely acute admissions (unplanned) and were significantly more likely to have treatments withheld or withdrawn compared with fit or pre-frail patients. Frailty was significantly associated with greater 30 -day all-cause mortality compared with those that were fit ( $41 \%$ for frail vs. $24 \%$ for fit; adjusted-hazards ratio 1.54; $95 \mathrm{CI}, 1.38-1.73$ ). Of interest, $23.8 \%$ of admitted patients did not receive any ICU-specific procedures.

The VIP study has several noteworthy findings. It builds further on prior work and affirms patients admitted to

\section{Springer}


ICU can be screened for frailty using a relatively simple tool, to provide a global impression of pre-hospital function [1-3]. Moreover, the CFS score appears to reliably predict a subgroup more likely to die within 30 daysconfirming construct validity.

Despite these insights, the VIP study has limitations that warrant some consideration. Despite being multicenter, the cohort may be susceptible to sampling bias given the variable contributions of participating countries [e.g., Great Britain 20.9\%, whereas others were represented by as few as six patients $(<1 \%)]$. Likewise, there may be selection bias by not having an understanding of the relative proportion of frail patients $\geq 80$ years of age denied ICU admission. In addition, there was limited adjustment in multi-variable analysis for multi-morbidity. Finally, to further build on prior work in this area, the VIP study would have been further strengthened by inclusion of confirmatory assessments of frailty status, and longer-term (post-hospitalization) outcomes including cognition, disability and disposition.

The findings of the VIP study have a number of potential implications. First, it was likely that very old patients were already carefully selected by intensivists for ICU admission, yet, despite this, an estimated two in five were screened as frail, illustrating the high prevalence in this demographic. This finding is of particular interest when juxtaposed with the fact that $23 \%$ of patients did not receive an ICU intervention (i.e., mechanical ventilation, vasoactive therapy, renal replacement therapy), although it is unclear how this interacts with the $31 \%$ of frail patients having treatments "withheld" or whether they simply were not indicated. Among those not receiving ICU interventions, it would be of interest to have insight into the reasons for ICU admission and whether this was reasonably warranted. Further work should aim to explore the implications of frailty for duration of organ support, and, perhaps due to diminished resilience, transition to a state of persistent critical illness [10]. In such circumstances, an appreciation of baseline functional and frailty status may help clinicians, patients and families navigate challenging decisions regarding offering and/or continuing advance life-support measures in ICU settings.

The burden of frailty in our ageing population is likely to increase and poses a significant health challenge [11]. The accrued evidence to date would imply frailty in ICU settings is important and that the integration of routine screening measures, such as the CFS, may add value by aiding in the identification of vulnerable patients, by providing incremental prognostic information, and by advancing research and innovation to improve patientcentred outcomes.

\section{Acknowledgements}

CM is supported by an Interdisciplinary Fellowship Award from the Canadian Frailty Network. SMB is supported by a Canada Research Chair in Critical Care Nephrology.

\section{Compliance with ethical standards}

\section{Conflict of interest}

The authors declare that they have no competing interests.

Received: 18 October 2017 Accepted: 20 October 2017

Published online: 30 October 2017

\section{References}

1. Bagshaw SM, Stelfox HT, McDermid RC, Rolfson DB, Tsuyuki RT, Baig N, Artiuch B, Ibrahim Q, Stollery DE, Rokosh E et al (2014) Association between frailty and short- and long-term outcomes among critically ill patients: a multicentre prospective cohort study. CMAJ 186:E95-E102

2. Brummel NE, Bell SP, Girard TD, Pandharipande PP, Jackson JC, Morandi A, Thompson JL, Chandrasekhar R, Bernard GR, Dittus RS et al (2017) Frailty and subsequent disability and mortality among patients with critical illness. Am J Respir Crit Care Med 196:64-72

3. Le Maquet $P$, Roquilly $A$, Lasocki $S$, Asehnoune $K$, Carise E, Saint Martin M, Mimoz O, Le Gac G, Somme D, Cattenoz C et al (2014) Prevalence and impact of frailty on mortality in elderly ICU patients: a prospective, multicenter, observational study. Intensive Care Med 40:674-682

4. Muscedere J, Waters B, Varambally A, Bagshaw SM, Boyd JG, Maslove D, Sibley S, Rockwood K (2017) The impact of frailty on intensive care unit outcomes: a systematic review and meta-analysis. Intensive Care Med 43:1105-1122

5. Rockwood K, Song X, Mitnitski A (2011) Changes in relative fitness and frailty across the adult lifespan: evidence from the Canadian National Population Health Survey. CMAJ 183:E487-E494

6. Gill TM, Gahbauer EA, Han L, Allore HG (2010) Trajectories of disability in the last year of life. N Engl J Med 362:1173-1180

7. Fassbender K, Fainsinger RL, Carson M, Finegan BA (2009) Cost trajectories at the end of life: the Canadian experience. J Pain Symptom Manage 38:75-80

8. Flaatten H, De Lange DW, Morandi A, Andersen FH, Artigas A, Bertolini G, Boumendil A, Cecconi M, Christensen S, Faraldi L et al (2017) The impact of frailty on ICU and 30-day mortality and the level of care in very elderly patients ( $\geq 80$ years). Intensive Care Med. https://doi.org/10.1007/ s00134-017-4940-8

9. Rockwood K, Song X, MacKnight C, Bergman H, Hogan DB, McDowell I, Mitnitski A (2005) A global clinical measure of fitness and frailty in elderly people. CMAJ 173:489-495

10. Iwashyna TJ, Hodgson CL, Pilcher D, Bailey M, van Lint A, Chavan S, Bellomo R (2016) Timing of onset and burden of persistent critical illness in Australia and New Zealand: a retrospective, population-based, observational study. Lancet Respir Med 4:566-573

11. Muscedere J, Andrew MK, Bagshaw SM, Estabrooks C, Hogan D, HolroydLeduc J, Howlett S, Lahey W, Maxwell C, McNally M et al (2016) Screening for frailty in Canada's Health Care System: a time for action. Can J Aging 35:281-297 